\section{'Taming' of the Wild Norway Rat by Rhinencephalic Lesions}

THE common Norway rat is a wild, fierce, aggressive animal which fights with other rats or other animals, large or small, at apparently slight provocation. When captured and brought into the laboratory such rats show no diminution of their aggressive tendencies even after months or years of the comparative safety and ease of laboratory life. They escape at the slightest opportunity and are difficult to recapture. They must always be handled carefully and with heavy gloves to avoid serious injury.

Several years ago, while working in Baltimore, I initiated a study of the effects of destruction of the amygdaloid nuclei in the brains of wild and domestic. ated Norway rats. It was thought at the time that observations made upon two strains of the same species-one wild, fierce and intractable; the other docile, friendly and easily handled-might throw some light upon the often disputed effects of such lesions upon emotional and sexual behaviour in animals.

As a result of some incidental observations on endocrine function in some of the wild rats ${ }^{1}$, attention was diverted and only a few domesticated rats were studied. Recently, the behaviour studies on wild rats have been repeated in a different laboratory (see present address), and it now seems worthwhile to report the striking changes in the behaviour of wild rats following the placement of lesions in the amygdaloid complex. Confirmation of the original observations has also been obtained elsewhere ${ }^{2}$.

To date, 42 wild rats with bilateral amygdaloid lesions have been studied. Control observations have been provided by : (I) both pre- and post-operative study of the behaviour of the operated rats; (2) twelve rats which were operated unilaterally in two stages with an intervening period of several weeks or months; (3) rats which were captured at the same time as the operated animals and were kept in the laboratory under identical conditions during the life-time of the operated animals; (4) sham operated rats.

None of the control animals has ever shown any observable change in behaviour.

On the other hand, either surgical or electrolytic intervention bilaterally in the area of the amygdala has inevitably produced 'tameness' in wild rats. Although eleven rats reverted to their pre-operative aggressiveness after a few days or weeks, thirty-one remained 'tame' for long periods (up to three years).

The most striking change in the behaviour of these rats is that, immediately following the operation, they no longer bite the experimenter. As soon as they recover from the anisthetic (ether) they can be handled without gloves and without fear of attack. Large (500-600 gm.) operated wild rats may be carried about for hours in the laboratory coat pocket without incident. They do not bite and they do not attempt to escape. Yet, they remain as alert and as active as before operation.

In addition to their behaviour with respect to handling, these rats have been observed when placed with other rats and with mice.

When white mice are introduced into a cage with normal wild rats, the mice are usually killed within a few seconds. On the other hand, wild rats with bilateral amygdaloid lesions rarely, if ever, molest the mice. In fact, they often exhibit a maternal-like grooming behaviour. This phase of the problem has been extensively studied and is reported elsewhere by Karli².

When wild rats are paired in the 'fighting chamber' designed by Richter ${ }^{3}$, they fight when given mild electrical shocks on their feet. Such fights are vicious and often end in death for one of the pair. Following operation, these animals rarely, if ever, attack their partner. Their post-operative behaviour is indistinguishable from that of domesticated rats under the same conditions.

The brains of seven wild rats which remained 'tame' for three months or more have been sectioned; but none has been completely reconstructed as yet. Gross inspection and microscopical study of the sections reveal that in no brain was the amygdala completely destroyed. In all cases damage was restricted to rhinencephalic structures.

Although the precise extent of the lesion necessary to produce these changes in behaviour is as yet. unknown, there seems to be little doubt that damage to the brain in the area of the amygdala produces an immediate, and in most cases permanent, loss of fierceness and aggressiveness in wild Norway rats. The mechanisms involved remain completely un. known.

\section{JAMES W. Woons}

(Fellow of the American Cancer Society) Department of Neuroendocrinology, Institute of Psychiatry,

Maudsley Hospital, London, S.E.5.

${ }^{1}$ Woods, James W., doctoral thesis, Johns Hopkins Univ. (1954). ${ }^{2}$ Karli, P., Behavior (in the press)

${ }^{3}$ Richter, C. P., Res. Publ. Assoc. Nerv. Ment. Dis., 29, 19 (1950),

\section{Heat Regulation of MaSarwa (Bushmen)}

Bushmen in their natural state fulfil two important. criteria for acclimatization to heat ${ }^{1}$. They probably are unique among indigenous peoples in this regard. In the first place, they are exposed to high tempera. tures and fairly intense radiation. Globe thermometer readings of $140^{\circ} \mathrm{F}$. in the sun and $104^{\circ} \mathrm{F}$. in the shade were recorded on our excursion into the Kalahari Desert. Secondly, these men are nomadic hunters, and, in tracking down and pursuing wild game, they exercise actively in these temperatures.

Four 'wild' Bushmen volunteered and were studied near Tsetsing, some 250 miles north-west of Molepolole in the Kalahari, Bechuanaland Protectorate. The experiments were conducted in a tent to eliminate the effects of direct solar radiation and of possible variations in wind velocity. In all other respects except one the routine followed closely upon that used for developing the Predicted 4-Hourly Sweat. Rate Index ${ }^{2}$. The exception is that mouth and not rectal temperatures were measured as the Bushmen refused the latter. By adding $1 \cdot 2^{\circ} \mathrm{F} . \pm 0 \cdot 6^{\circ} \mathrm{F}$, mouth temperature can be converted to rectal tem. perature with reasonable accuracy ${ }^{3}$.

The small size of the Bush people compared with Europeans is made clear in Table 1. The resting metabolic rate was close to that of the Singapore naval rating ${ }^{4}$; but the metabolic cost of work was closer to that of the Queen's Square subjects. Hence the amount of heat to be dissipated per unit surface area by Bushmen is similar to thai of Europeans. Under conditions of mild heat stress, namely, $88^{\circ} \mathbf{F}$. air tempera'jure, $72^{\circ} \mathrm{F}$. wet bulb temperáure and globe temperature of $92^{\circ} \mathrm{F}$., which has a Sweat-Rate. 